\title{
Detection of Proximal Caries at The Molar Teeth Using Edge Enhancement Algorithm
}

\author{
Jufriadif Na am ${ }^{1}$, Johan Harlan ${ }^{2}$, Sarifuddin Madenda ${ }^{3}$, Julius Santony ${ }^{4}$, Catur Suharinto ${ }^{5}$ \\ ${ }^{1,4}$ Faculty of Computer Science, Universitas Putra Indonesia YPTK Padang, Indonesia \\ ${ }^{2,3}$ Faculty of Computer Science, Universitas Gunadarma, Indonesia \\ ${ }^{5}$ Department of Radio Diagnostic and Therapy, Universitas Baiturrahmah, Indonesia
}

\begin{tabular}{l} 
Article Info \\
\hline Article history: \\
Received Jan 31, 2018 \\
Revised Feb 28, 2018 \\
Accepted Aug 13, 201 \\
\hline Keyword: \\
Algorithm \\
Edge detection \\
Edge enhancement \\
Molar teeth \\
Proximal caries
\end{tabular}

\begin{abstract}
Panoramic X-Ray produces the most common oral digital radiographic image that it used in dentistry practice. The image can further improve accuracy compared to analog one. This study aims to establish proximal caries edge on enhancement images so they can be easily recognized. The images were obtained from the Department of Radiology, General Hospital of M. Djamil Padang Indonesia. Total file of images to be tested were 101. Firstly, the images are analyzed by dentists who practiced at Segment Padang Hospital Indonesia. They concluded that there is proximal caries in 30 molar teeth. Furthermore, the images were processed using Matlab software with the following steps, i.e. cropping, enhancement, edge detection, and edge enhancement. The accuracy rate of detection of edge enhancement images being compared with that of dentist analysis was 73.3\%. In the edge enhancement images proximal caries edge can be found conclusively in 22 teeth and dubiously in eight teeth. The results of this study convinced that edge enhancement images can be recommended to assist dentists in detecting proximal caries.
\end{abstract}

Copyright (c) 2018 Institute of Advanced Engineering and Science. All rights reserved.

\section{Corresponding Author:}

Jufriadif Na`am, Faculty of Computer Science, Universitas Putra Indonesia YPTK Padang, Jl. Raya Lubuk Begalung Padang, 25221, Indonesia.

Email: jufriadifnaam@gmail.com

\section{INTRODUCTION}

Tooth decay also called dental cavities or dental caries. One type of dental caries detected using radiographic images is proximal or interproximal caries [1]. Caries is a problematic diagnosis [2]. The proximal tooth surface can hardly be approached or visualized directly, therefore, the caries on this surface are often diagnosed with the aid of radiographs [3]. Various methods in radiography have been performed to diagnose proximal caries [4-6]. Each method has its techniques, advantages, and disadvantages. But automatic diagnosis is still a challenging and unsolved problem [7], so that suitable technique is required in certain situations [8].

The radiographic image is the image used to prove the dentist's perception in diagnosing the dental caries disease [9]. Panoramic radiography produces an image that includes both maxillary and mandibular dental arches and the surrounding structures [10][11]. This image has an important role in clinical diagnosis and dental care. The dental clinical diagnosis usually includes the disease, the type of disease and the severity of the disease on the teeth. The image generated from radiography does not provide sufficient detail for tooth decay treatment and treatment procedures as it often overlaps with anatomical structures [12].

The machine of Panoramic X-Ray produces two outputs, namely analog (film) and digital images. Panoramic digital image provides better accuracy than analog [13], but the accuracy is still low in 
comparison to other mode of radiographic image in caries detection [14]. And there was no significant difference in proximal caries detection using a variety of radiographic modes [15].

To observe the information in Panoramic X-Ray digital images more easily; it is necessary to perform image processing to improve the quality of the medical image [16]. Several studies have been done to improve the quality of the image to diagnose dental caries. Valizadeh et al. (2015) conducted a study to develop and assess the function of diagnostic computer software designed for evaluation of approximal caries in posterior teeth [17]. Miri et al. (2015) conducted a study evaluated the diagnostic accuracy of the reverse contrast mode in intraoral digital radiography for the detection of proximal dentinal caries, in comparison with the original digital radiographs [18]. Na'am et al. (2017) conducted a study to facilitate the identification of proximal caries in the Panoramic Dental X-Ray image [19]. Tikhe et al. (2016) conducted a study to present an algorithm using digital periapical radiographic images to detect enamel caries and interproximal caries [20].

In this study, we proposed a method of digital image processing of Panoramic X-Ray in edge detection to enhance image of proximal caries on molar tooth. The edge of teeth that curved into the tooth area is the identity of the proximal caries. The result of the digital detection is compared with clinical diagnosis of the dentist to obtain the level of accuracy of the study.

\section{RESEARCH METHOD}

This study aims to establish a proximal caries tooth edge in a digital image of molar teeth with improved quality. The stages of image processing performed are Cropping, Filtering, Enhancement, Segmentation, and Edge Detection with the result of enhanced edge detection. The whole process will produce four image files, i.e., as cropping image, enhancement image, edge detection image and enhancement image that has formed edge detection. Stages of the process performed are shown in Figure 1.

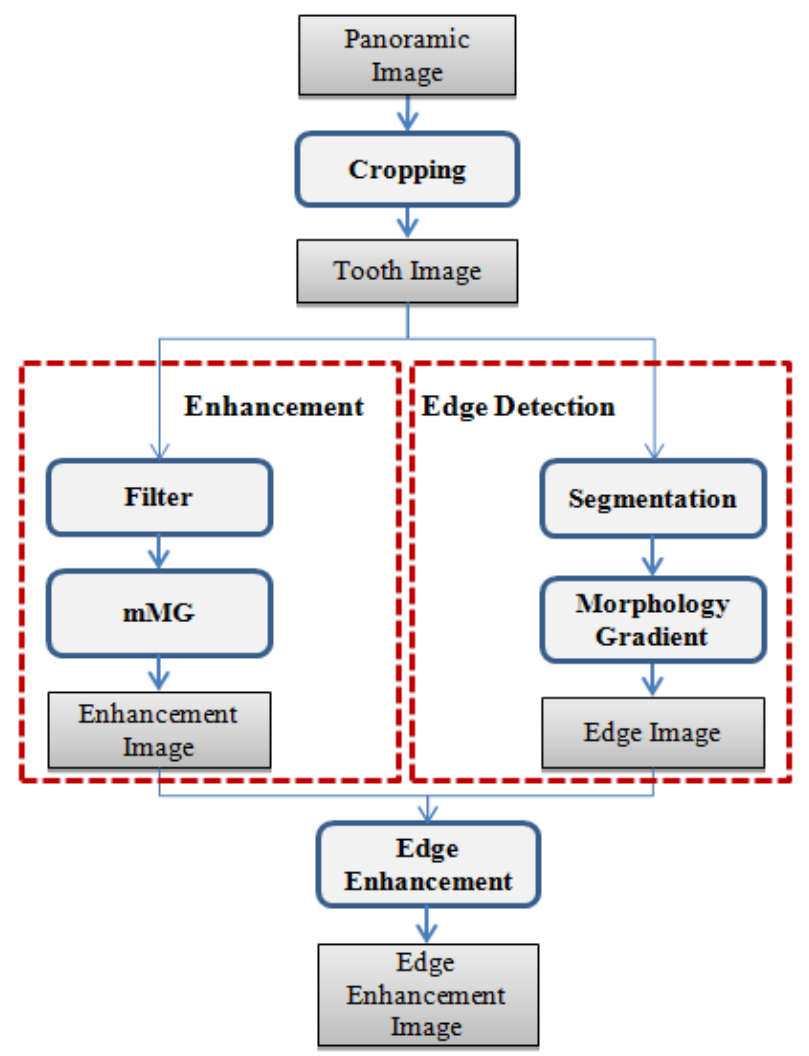

Figure 1. Stages of Image Processing

Images of this research data were obtained from the Radiology of Central General Hospital Dr. M. Jamil Padang Indonesia. The hospital is a government type B as educational hospital located in the city of Padang, Indonesia. The Panoramic X-Ray equipment used in this hospital is branded Pantos DG XP 
products from BlueX Italia. This tool produces an image plate with a size of $15 \times 30$ centimeters and gray level digital image with Portable Network Graphics (PNG) format. The pixel size of the digital image is 2764x1330 pixels. In Figure 2 below is one of Panoramic X-Ray digital image that is processed and has its tooth numbering.

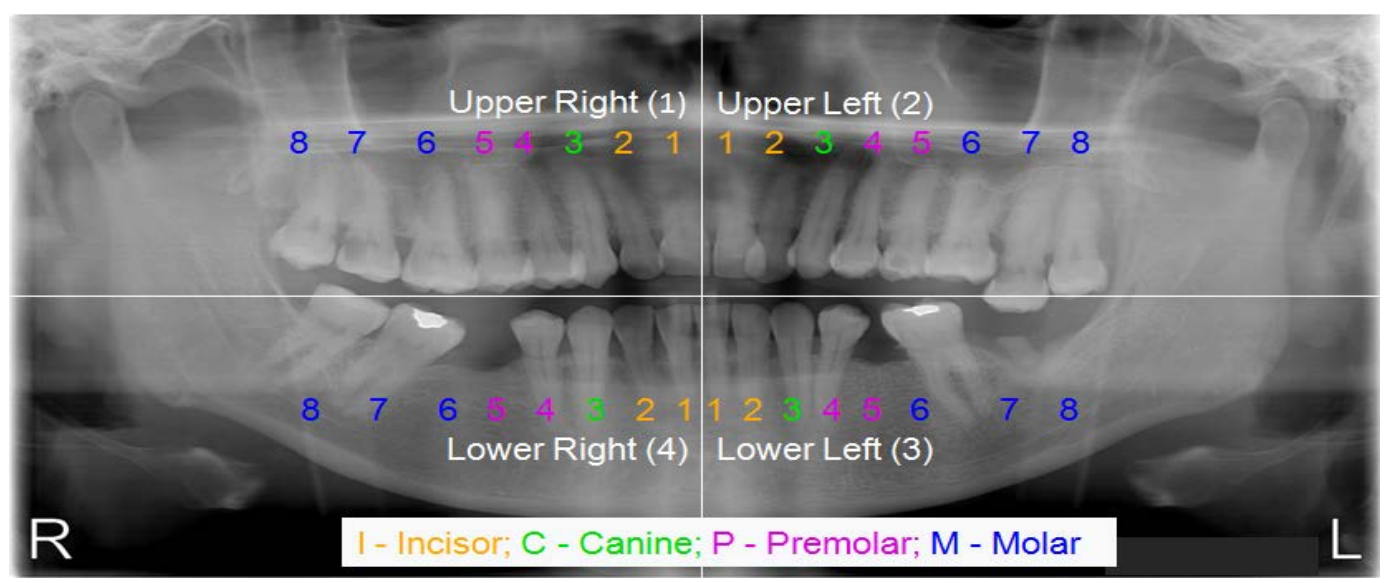

Figure 2. Notation of teeth [21]

The total of digital images processed in this study was 101 images. All images analyzed by dentists of Semen Padang Hospital to detect proximal caries in a molar tooth. The result of the analysis was that there were 23 Panoramic X-Ray images of proximal or interproximal caries. Previously, these photos were used to study accuracy using multiple Morphological Gradient (mMG) [22]. In these 23 Panoramic X-Ray images, there are 30 molar teeth of proximal caries sufferers. These 30 teeth images were processed in this study with Matlab software.

\section{RESULTS AND ANALYSIS}

The image presented in this paper is Panoramic X-Ray image in Figure 2. The result of analysis by the dentist that there are proximal caries in the molar teeth, i.e. number 17 (upper right number 7) and 27 (upper left number 7). Furthermore, we proceed with cropping process.

\subsection{Cropping}

The cropping is the process of taking the tooth area to be processed next. The cropping technique used in this study was still manual [23]. This method produces a square area with the determination of the starting point which is drawn diagonally. The diagonal starting point could start at any point, such as the upper left; top right; bottom left; or bottom right. Next we draw the diagonal to get the endpoint, so that the cropping area model could select one of the following four models, such as Figure 3. The cropping model used for the test image is from the top right to the lower left. The cropped image is shown in Figure 4. The cropped image represents the area of the proximal caries that has been separated from the Panoramic X-Ray area. This area is already separating the teeth for the next process.

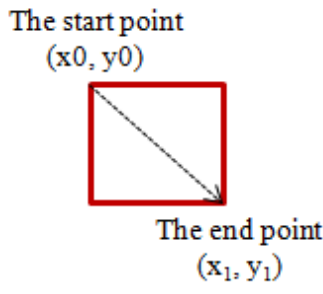

(a)

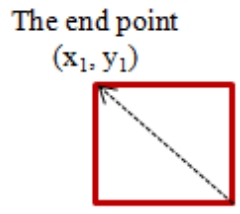

The start point $(\mathrm{x} 0, \mathrm{y} 0)$

(b)

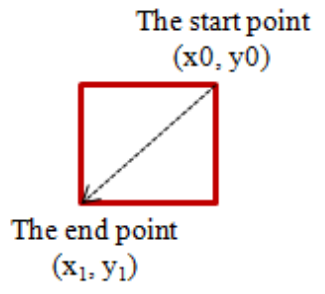

(c)

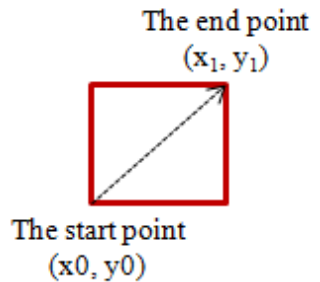

(d)

Figure 3. Models of cropping area (a) the top left to the bottom right, (b) the right down to the top left, (c) top right to the bottom left, (d) the bottom left to the top right 


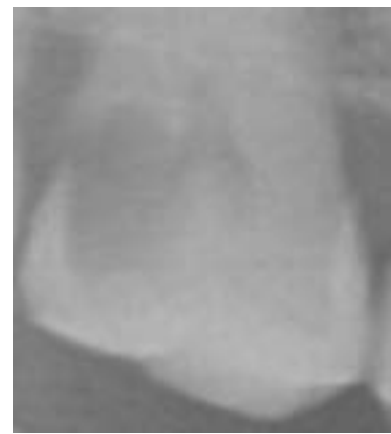

(a)

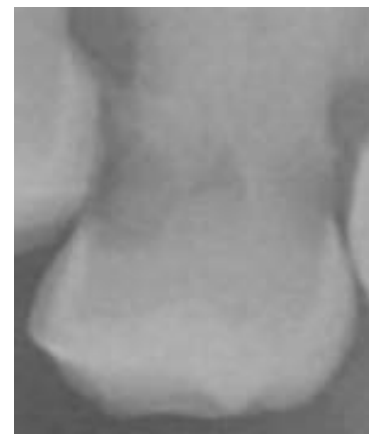

(b)

Figure 4. The cropping image (a) 17th tooth, (b) 27th tooth

\subsection{Enhancement}

Image quality and accuracy are the core factors, image quality assessment, as well as improvement, are depending on the enhancement [24], [25]. Enhancement aims to improve image quality while edge detection form the edge of the tooth. Both of these processes have different algorithms, so both processes were separated. Enhancement aims to clarify the information contained in the cropped image. Enhancement process consists of two stages, namely Filtering and mMG. The filtering is the process of removing noise that is eliminating the pixel value that is too low, or the value that is too high from the value of surrounding pixels in an image. These noise pixels are scattered randomly and improperly. The filtering technique is performed using Gaussian method [26]. Next, the filtered image is processed by mMG method [27]. The result of Enhancement images process can be seen in Figure 5.

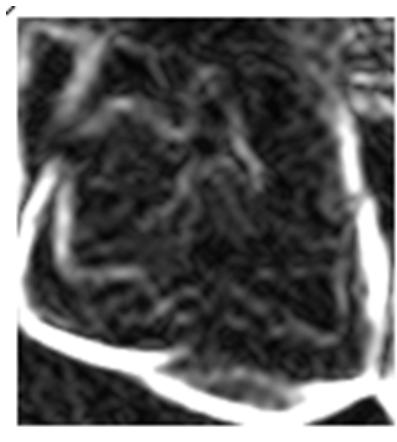

(a)

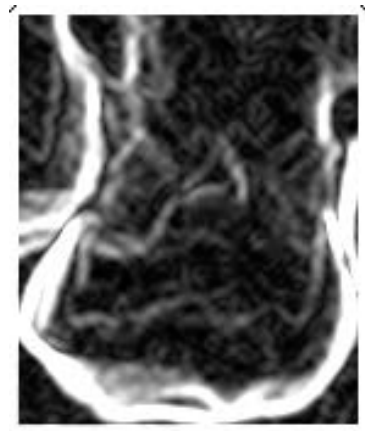

(b)

Figure 5. The result of enhancement process (a) 17th tooth, (b) 27th tooth

In the enhancement process it has been able to form objects clearly. This method works to increase the pixel value that makes up the object and the pixel value of the fixed background. However, the edge of the object has not been set clearly. The reason is that the difference in pixel values of objects is not so significant. For that, a separate process for edge detection is performed.

\subsection{Edge Detection}

The edge detection process aims to form the edge of each object of the cropped image clearly. This process consists of 2 stages, namely segmentation and forming an edge. Medical image segmentation will seek to improve the accuracy, precision, and computing speed of the segmentation method, as well as reduce the number of manual interactions [28]. Process segmentation is performed using Otsu [29], and edge technique is performed using Morphology Gradient. The purpose of Morphology Gradient is to reduce the result of Dilation Morphology with Erosion Morphology [30]. The equation as follows:

$\operatorname{Ed}=\operatorname{Md}(0)-M e(0)$ 
where: Ed: The result of edge detection image

Md: Dilation morphology

Me: Erosion morphology

o: The result of Otsu image

The result of edge detection image can be seen in Figure 6. In the result of edge detection image, the boundary edge of the object has been formed clearly.

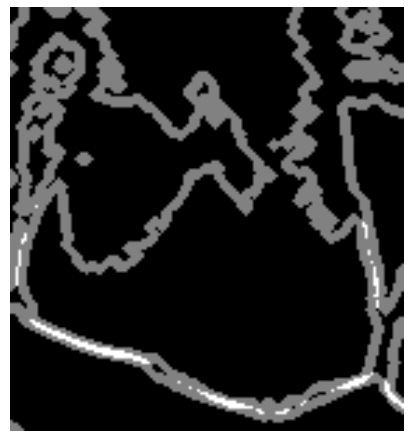

(a)

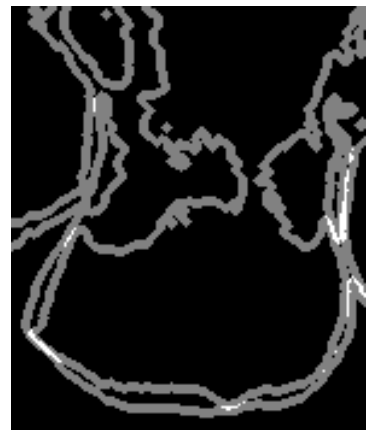

(b)

Figure 6. The result of edge detection process (a) 17th tooth, (b) 27 th tooth

\subsection{Edge Enhancement}

Furthermore, the process of forming edge detection of enhancement image based on the pixel of edge position on edge detection image. So to clarify the edge borders on the enhancement is the formation of edges based on a pixel position at edge detection. The edge pixel position on the edge detection image is adjusted to the location of the enhancement image and then replaced with the highest value in the enhancement image. Then the edges of the image enhancement can be seen clearly. The algorithm used edge enhancement with equation as follows:

$$
\operatorname{mMG}(\mathrm{x}, \mathrm{y})=\operatorname{mMGmax} \mid \operatorname{Ed}(\mathrm{x}, \mathrm{y})=128
$$

Code of algorithm is as follows:

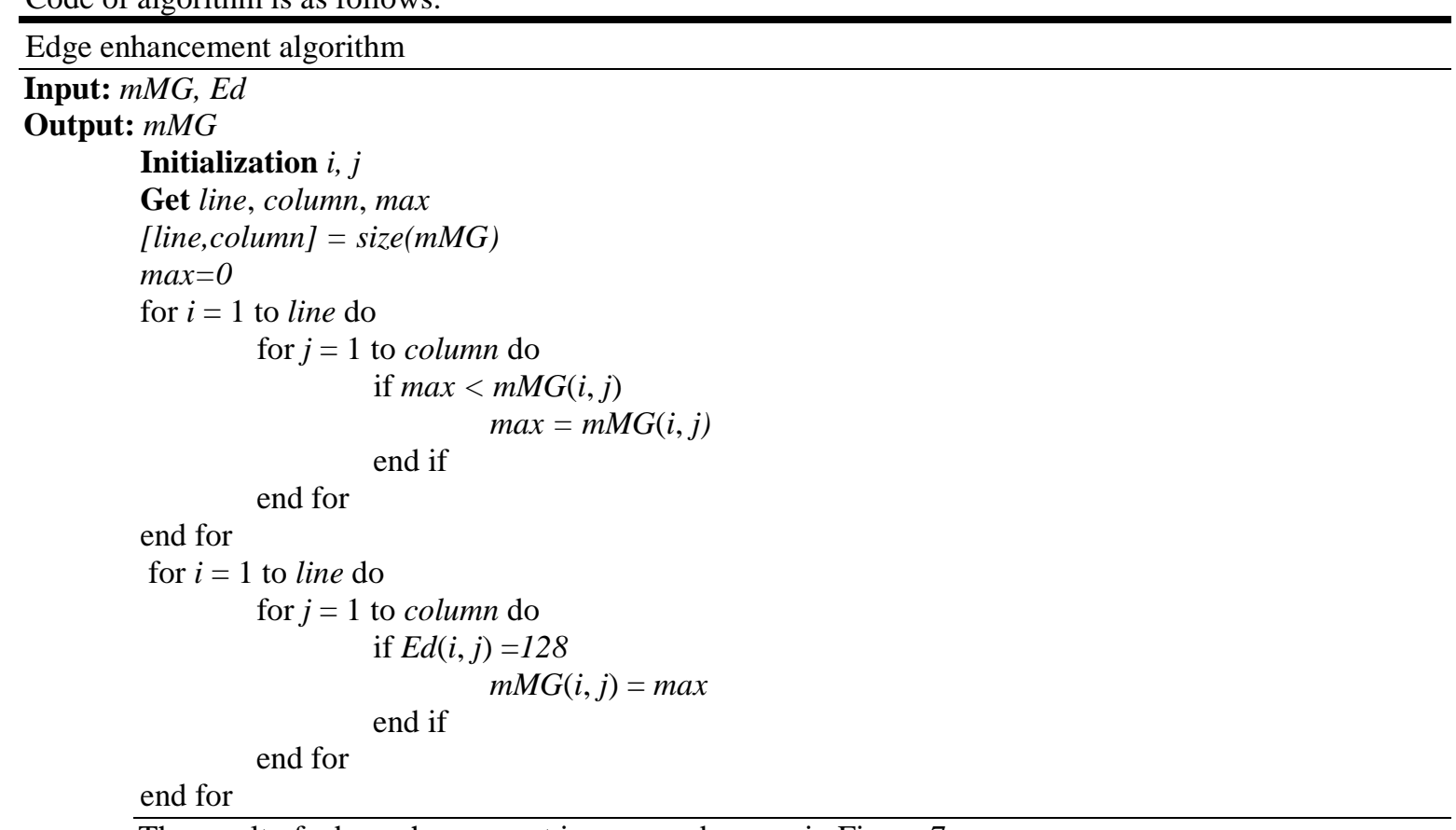

The result of edge enhancement image can be seen in Figure 7. 


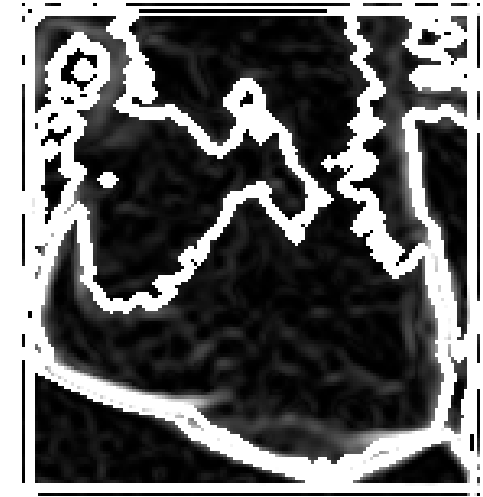

(a)

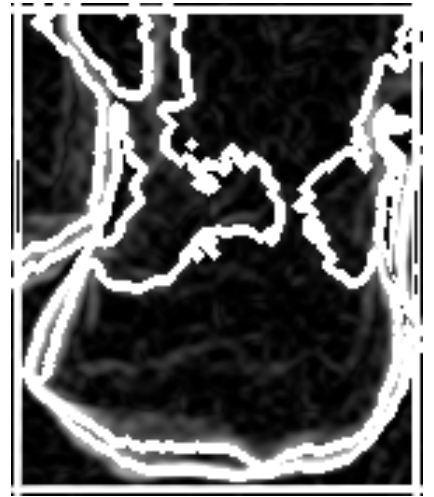

(b)

Figure 7. The result of edge enhancement process (a) 17th tooth, (b) 27th tooth

Edge enhancement results have been clearly detected directly against the proximal caries, the edge of the tooth that protrudes into the tooth. The entire process tested on 30 molar teeth found in proximal caries that have been analyzed by the dentist. The detection result is 22 recognized from 30 teeth. Thus, the accuracy is as follows:

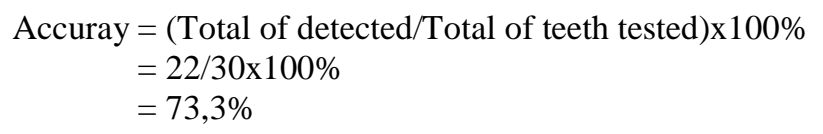

So the accuracy of this method is $73.3 \%$.

\section{CONCLUSION}

Based on the image tested, that can form edge on the image enhancement as the edge of proximal caries, this study may be recommended to assist dentists in reducing the hesitation in detecting proximal caries. The existence of an unclear edge, because the edge of caries overlaps with the edge of other teeth.

\section{ACKNOWLEDGEMENTS}

We thank the Head of Department of Radiology, General Hospital of M. Djamil Padang-Indonesia who have allowed us to use data from the department. We would also like to thank the dentists of Semen Padang Hospital who have helped us in the initial analysis of images which were used in this study.

\section{REFERENCES}

[1] A. Abdelfattah, “Oral Health, Diseases, Examination, Diagnosis, Treatment Plan \& Mouth Preparation,” Advances in Dentistry \& Oral Health, vol. 3, pp. 1-13, Nov. 2016.

[2] J. B. Summit, et al., "Fundamentals of Operative Dentistry; A Contemporary Approach," Quintessenz Verlag: Berlin, pp. 31, 2006.

[3] X. Qu, et al., "Detection accuracy of in vitro approximal caries by cone beam computed tomography images," Eur J Radiol, vol. 79, pp. e24-e27, 2011.

[4] N. Farhadi, et al., "Effect of different levels of sharpness processing filter on the measurement accuracy of endodontic file length,” Dental Hypotheses, vol. 7, pp. 15-19, Mar. 2016.

[5] M. K. Zayet, et al., "Effect of changing the kilovoltage peak on radiographic caries assessment in digital and conventional radiography,” Imaging Science in Dentistry, vol. 14, pp. 199-205, Apr. 2014.

[6] Z. D. Kajan, et al., "The effects of noise reduction, sharpening, enhancement, and image magnification on diagnostic accuracy of a photostimulable phosphor system in the detection of non-cavitated approximal dental caries,” Imaging Science in Dentistry, vol. 45, pp. 81-87, Apr. 2015.

[7] C. Wang, et al., "A benchmark for comparison of dental radiography analysis algorithms," Medical Image Analysis, vol. 31, pp. 63-76, Feb. 2016.

[8] R. Periyasamy, et al., "Detection of dental caries,”, International Journal of Current Research, vol. 9, pp. 5416354167, Jul. 2017. 
[9] E. E. Coche, “Chest Radiography Today and Its Remaining Indications,” In: A. L. Baert, M. F. Reiser, H. Hricak, and Knauth, Editors Comparative Interpretation of CT and Standard Radiography of the Chest, Springer-Verlag Berlin Heidelberg, pp. 3-26, 2011.

[10] P. C. A. Watanabe, et al., "Multiple Radiographic Analysis (Systemic Disease): Dental Panoramic Radiography," Journal of Oral Health and Dental Care, vol. 1, pp. 1-7, Jan. 2017.

[11] R. Supriyanti, et al., "Point Processing Method for Improving Dental Radiology Image Quality,” International Journal of Electrical and Computer Engineering (IJECE), vol. 6, pp. 1587-1594, Apr. 2016.

[12] T. A. Ajins, et al., "Imaging Modalities for General Dental Practice - Bird 's Eye View," Journal of Academy of Dental Education, vol. 2, pp. 11-14, Sep. 2016.

[13] A. Sabarudin and Y. J. Tiau, "Image quality assessment in panoramic dental radiography: a comparative study between conventional and digital systems," Quantitative imaging in medicine and surgery, vol. 3, pp. 43-48, Feb. 2013.

[14] F. Fallahzade, et al., "A Comparison of The Diagnostic Accuracy of Digial Bitewing and Digital Panoramic Radiogrphies in The Detection of Proximal Caries,” Annals of Dental Specialty, vol. 5, pp. 41-44, Jun. 2017.

[15] G. L. Terry, et al., "A clinical comparison of extraoral panoramic and intraoral radiographic modalities for detecting proximal caries and visualizing open posterior interproximal contacts,” Dentomaxillofacial Radiology, vol. 45, pp. 1-7, Feb. 2016.

[16] W. Gunawan, et al., "Fuzzy Region Merging Using Fuzzy Similarity Measurement on Image Segmentation," International Journal of Electrical and Computer Engineering (IJECE), vol. 7, pp. 3402-3410, Sep. 2017.

[17] S. Valizadeh, et al., "Designing of a computer software for detection of approximal caries in posterior teeth," Iranian Journal of Radiology, vol. 12, pp. 1-8, Oct. 2015.

[18] S. Miri, et al., "The efficacy of the reverse contrast mode in digital radiography for the detection of proximal dentinal caries,” Imaging Science in Dentistry, vol. 45, pp. 141-145, Apr. 2015.

[19] J. Na`am, et al., "Image Processing of Panoramic Dental X-Ray for Identifying Proximal Caries,” TELKOMNIKA, vol. 15, pp. 702-708, Jun. 2017.

[20] S. V. Tikhe, et al., "Algorithm to Identify Enamel Caries and Interproximal Caries Using Dental Digital Radiographs,” IEEE 6th International Advanced Computing Conference (IACC), pp. 225-228, 2016.

[21] A. Blinkhorn, et al., "An investigation into the use of the FDI tooth notation system by dental schools in the UK," Eur J Dent Educ, vol. 2, pp. 39-41, Oct. 1997.

[22] J. Na`am, "Accuracy of Panoramic Dental X-Ray Imaging in Detection of Proximal Caries with Multiple Morpological Gradient (mMG) Method,” International Journal on Informatics Visualization, vol. 1, pp. 5-11, Mar. 2017.

[23] J. Na`am, et al., "Detection of Infiltrate on Infant Chest X-Ray,” TELKOMNIKA, vol. 15, pp. 1943-1951, Dec. 2017.

[24] G. Sivaradje, et al., "LEGION_Based Segmentation of Magnetic Resonance Images of the Brain,” IETE Journal of Research,vol. 48, pp. 311-315, Aug. 2002.

[25] H. Gupta, et al., "Resource Efficient FPGA Implementation of Adaptive Image Enhancement Algorithms," IETE Journal of Research, vol. 61, pp. 429-439, May 2015.

[26] R. A. Haddad and A. N. Akansu, "A Class of Fast Gaussian Binomial Filters for Speech and Image Processing," IEEE Transactions on Signal Processing, vol. 39, pp. 723-727, Mar. 1991.

[27] J. Na`am, et al., "Identification of the Proximal Caries of Dental X-Ray Image with Multiple Morphology Gradient Method,” International Journal on Advanced Science, Engineering and Information Technology (IJASEIT), vol. 6, pp. 343-346, Jun. 2016.

[28] D. I. Lanlege, et al., “The iris biometric feature segmentation using finite element method," Leonardo Journal of Sciences, vol. 26, pp. 1-16, 2015

[29] N. Otsu, "A threshold selection method from gray-level histograms," IEEE Trans. Sys. Man. Cyber, vol. SMC-9, pp. 62-66, Jan. 1991.

[30] D. P. Lestari, et al., "Comparison of Three Segmentation Methods for Breast Ultrasound Images Based on Level Set and Morphological Operations,” International Journal of Electrical and Computer Engineering (IJECE), vol. 7, pp. 383-391, Dec. 2016.

\section{BIOGRAPHIES OF AUTHORS}

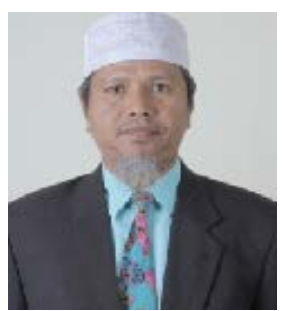

Jufriadif Na am was born in Padang, Indonesia, in 1967. He is an associate Professor in Computer Science Department, Universitas Putra Indonesia YPTK. He received the Bachelor Degree in Management Informatics and Master Degree in Information Tecnology in 1994 and 2006 from Universitas Putra Indonesia YPTK. Moreover, he completed his Doctorate of Information Technology as Medical Image expertise from Gunadarma University in January 2017. He is member of IEEE (94313333). Currently, he has been researching on Algorithms and Medical Images.

E-mail: jufriadifnaam@gmail.com 


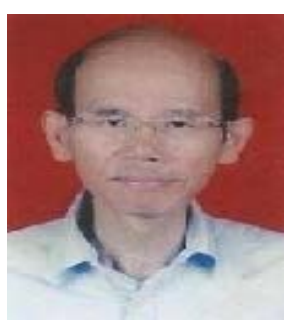

Johan Harlan is a medical doctor, professor in medical informatics and head of reseach center of medical informatics of Gunadarma University. He obtained his PhD in 2003 and has been the lecturer in doctoral department of information technology of Gunadarma University since 2004. He was one of the founders of Indonesian Health Informatics Association in 2005. His area of expertise encompasses medical statistics and clinical epidemiology.

E-mail: harlan_johan@hotmail.com

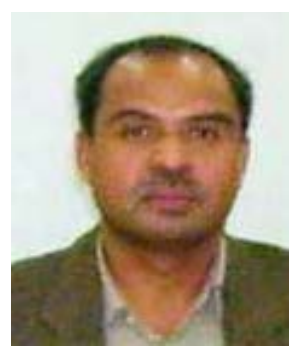

Sarifuddin Madenda - Currently, Director of Doctoral Programs in Information Technology \& Computer Science, Gunadarma University. He received the B.S. degree from University of Indonesia, in 1989, the Master degree from Institute National des Sciences Appliquées de Lyon (INSA de Lyon) - French, in 1992, and the Ph.D. degree from University of Burgundy-French, in 1995. From 1995 to 1996, he was a Research Associate at LIESIB Laboratory - University of Burgundy. In 1997, he became a Lecturer in Computer Science Department, Gunadarma University-Indonesia. From 2002 to 2007, he was a researcher at Academic Research Consortium on digital imaging, video, audio and multimedia (CoRIMedia), Canada. He was an associate professor at Université du Québec en Outaouais, Canada. His research interests are image processing: image compression, color imaging analysis, image database and searching, medical image analysis, implementing of image processing algorithms on FPGA for real-time image analysis.

E-mail: sarif@staff.gunadarma.ac.id

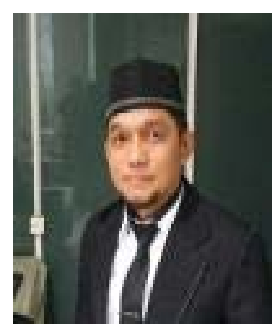

Julius Santony was born in Padang Panjang, Indonesia, in 1973. He is an Associate Professor in Computer Science Department, Universitas Putra Indonesia YPTK. He received the Bachelor Degree in Informatics Management in 1996 from Gunadarma University and Master Degree in Information Tecnology in 2006 from Universitas Putra Indonesia YPTK. Moreover, he completed his Doctorate of Information Technology as Medical Image expertise from Gunadarma University in December 2015. He is member of Scopus (57189362021). Currently, he has been researching on Algorithms and Medical Images.

E-mail: juliussantony@yahoo.co.id

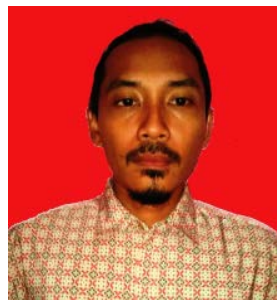

Catur Suharinto was born in Grobogan, Indonesia in 1982. He is a Electromedical Engineer in M Djamil General Hospital and a lecturer in Radiographic and radiotherapy technique departement, Universitas Baiturrahmah. He received electromedical engineering diploma degree in 2004 from Akademi teknik elektromedik Widya Husada. He received bachelor of Applied Science in Electronics instrumentation from STTN BATAN in 2014. He received Master Degree in Information Tecnology from Universitas Putra Indonesia YPTK in 2017. Currently, he has been researching on biomedical sensor and medical images.

E-mail: catur3414@gmail.com 